\title{
Default Network Connectivity in Medial Temporal Lobe Amnesia
}

\author{
Scott M. Hayes, ${ }^{1,2}$ David H. Salat, ${ }^{2,3}$ and Mieke Verfaellie ${ }^{1}$ \\ ${ }^{1}$ Memory Disorders Research Center, VA Boston Healthcare System and Boston University School of Medicine, and ${ }^{2}$ Neuroimaging Research for Veterans \\ Center, VA Boston Healthcare System, Boston, Massachusetts 02130, and ${ }^{3}$ Athinoula A. Martinos Center for Biomedical Imaging, MGH Radiology, \\ Charlestown, Massachusetts 02129
}

There is substantial overlap between the brain regions supporting episodic memory and the default network. However, in humans, the impact of bilateral medial temporal lobe (MTL) damage on a large-scale neural network such as the default mode network is unknown. To examine this issue, resting fMRI was performed with amnesic patients and control participants. Seed-based functional connectivity analyses revealed robust default network connectivity in amnesia in cortical default network regions such as medial prefrontal cortex, posterior medial cortex, and lateral parietal cortex, as well as evidence of connectivity to residual MTL tissue. Relative to control participants, decreased posterior cingulate cortex connectivity to MTL and increased connectivity to cortical default network regions including lateral parietal and medial prefrontal cortex were observed in amnesic patients. In contrast, somatomotor network connectivity was intact in amnesic patients, indicating that bilateral MTL lesions may selectively impact the default network. Changes in default network connectivity in amnesia were largely restricted to the MTL subsystem, providing preliminary support from MTL amnesic patients that the default network can be fractionated into functionally and structurally distinct components. To our knowledge, this is the first examination of the default network in amnesia.

\section{Introduction}

Subsequent to the initial report that bilateral resection of the medial temporal lobes (MTL) results in profound anterograde amnesia (Scoville and Milner, 1957), the MTL have taken center stage in the examination of the neural underpinnings of human memory (O'Keefe and Nadel, 1978; Squire et al., 2004; Eichenbaum et al., 2007). Recently, neuroimaging studies have highlighted the MTL as part of a large-scale neural system know as the default network (DN) (Greicius and Menon, 2004), which also includes posterior cingulate/precuneus, bilateral parietal cortex, and medial prefrontal cortex (Raichle et al., 2001; Buckner et al., 2008). The DN is active when subjects are at rest, that is, not directly attending to an external stimulus. Importantly, a substantial amount of cognitive processing that occurs during rest or low-level control tasks involves episodic memory retrieval (Andreasen et al., 1995; Mazoyer et al., 2001). Consequently, significant overlap in brain regions associated with episodic and

Received Feb. 9, 2012; revised July 11, 2012; accepted Aug. 24, 2012.

Author contributions: S.M.H., D.H.S., and M.V. designed research; S.M.H. performed research; S.M.H. analyzed data; S.M.H. and M.V. wrote the paper.

This work was supported by the Department of Veterans Affairs Rehabilitation Research and Development Service (Career Development Award e7822w to S.M.H.), Clinical Science Research and Development Service (to M.V.), and the National Institutes of Health (Grant R01 MH093431). We thank Amanda Mikedis for assistance with MRI data collection, Dr. Ginette Lafleche for clinical neuropsychological assessment, and Dr. Margaret Keane for helpful comments and discussion.

The authors declare no financial conflicts of interest.

Correspondence should be addressed to Dr. Scott M. Hayes, Memory Disorders Research Center (151A), VA Boston Healthcare System, 150 South Huntington Ave, Boston, MA 02130. E-mail: smhayes@bu.edu.

DOI:10.1523/JNEUROSCI.0700-12.2012

Copyright $\odot 2012$ the authors $\quad 0270-6474 / 12 / 3214622-08 \$ 15.00 / 0$ autobiographical memory and the DN has been identified (Daselaar et al., 2009; Spreng et al., 2009).

Although episodic memory has been linked to the DN, little is known about the impact of extensive MTL damage (and associated severe memory impairment) on DN connectivity. Do regions that are remote but connected to MTL experience changes in neural connectivity (diaschisis) (Price et al., 2001)? Do intact nodes exhibit functional compensation in response to extensive MTL damage (Addis et al., 2007)? Previous work has examined the impact of neurodegenerative processes, such as Alzheimer's disease, on the DN (Greicius et al., 2004; Buckner et al., 2009; Sperling et al., 2010), but Alzheimer's disease pathology is widespread, and impacts the same heteromodal association cortices associated with the DN, making it difficult to attribute change to particular nodes or subsystems. Studies of epilepsy focus on patients with unilateral MTL dysfunction (Frings et al., 2009; Liao et al., 2011), which results in more subtle episodic memory changes than those observed in amnesia (performance is typically within normal limits but statistically decreased relative to controls). Thus, the impact of bilateral lesion to an important node of the DN (MTL) sufficient to cause amnesia remains unknown.

An attractive feature of the DN is that it can be identified using a seed-based connectivity approach during rest or low-level task conditions (Greicius et al., 2003). This approach holds particular appeal for application in patients who, due to cognitive limitations, are unable to complete task-related paradigms or might perform at floor level. Identification of resting state connectivity allows one to examine the integrity of neural networks such as the DN that have been linked to episodic memory, independent of 


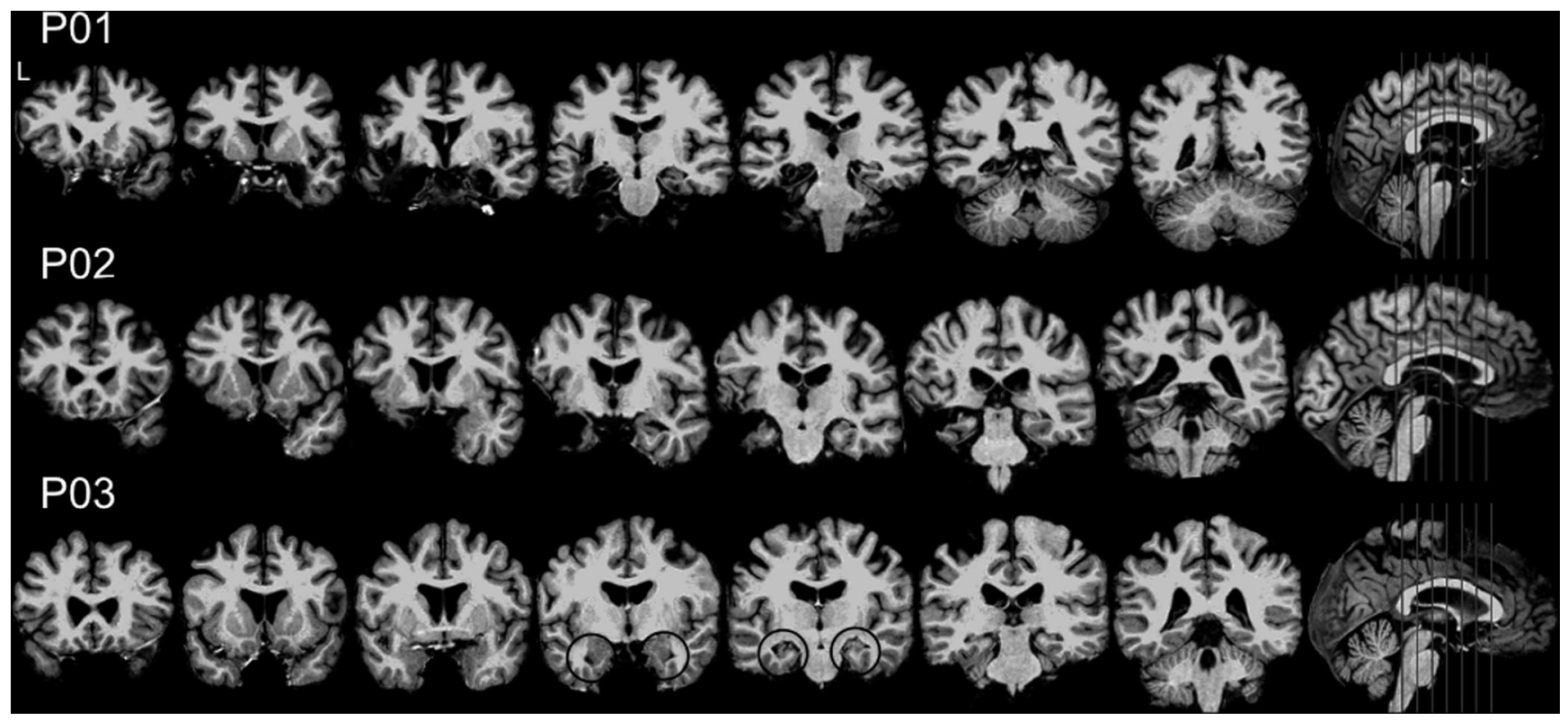

Figure 1. Lesion profile illustrating bilateral medial temporal lobe damage in each amnesic patient. P03's bilateral hippocampal atrophy is highlighted with black circles.

Table 1. Demographic and neuropsychological characteristics of three amnesic patients and 10 matched controls

\begin{tabular}{|c|c|c|c|c|c|c|c|c|}
\hline Subject & Etiology & Age (years) & $\begin{array}{l}\text { Education } \\
\text { (years) }\end{array}$ & VIQ & WM & GM & VD & $A D$ \\
\hline P01 & Encephalitis & 55 & 14 & 92 & 85 & 45 & 56 & 55 \\
\hline $\mathrm{P} 02$ & $\begin{array}{l}\text { Status epilepticus, } \\
\text { Anoxia }\end{array}$ & 47 & 16 & 86 & 93 & 49 & 53 & 52 \\
\hline $\begin{array}{l}\text { P03 } \\
\text { Controls (SD) }\end{array}$ & Anoxia & $\begin{array}{l}56 \\
54(5.1)\end{array}$ & $\begin{array}{l}14 \\
16.7(1.8)\end{array}$ & $\begin{array}{l}111 \\
111(14)\end{array}$ & 96 & 59 & 72 & 59 \\
\hline
\end{tabular}

$\mathrm{AD}$, Auditory delayed memory; GM, general memory; $\mathrm{VD}$, visual delayed memory; VIQ, verbal IQ; WM, working memory.

task performance. In the current study, we sought to characterize a large-scale neural network associated with episodic memory, the DN, in patients with amnesia secondary to bilateral MTL lesions. Using a seed-based approach, we first assessed DN connectivity at the individual subject level in amnesic patients. Next, we examined changes in intrinsic functional connectivity common to MTL amnesia.

\section{Materials and Methods}

Participants. Three male amnesic patients and 10 age- and educationmatched control participants (seven males) recruited from the Boston community were screened for contraindications to MRI and participated in the study. The extent of MTL damage varied across the three amnesic patients (Fig. 1). Formal neuropsychological testing of amnesic patients revealed that each patient performed within the severely impaired range on Wechsler Memory Scale-III indices of immediate and delayed episodic memory; in each case, these indices were $>2$ standard deviations (SD) below their verbal IQ as measured by the Wechsler Adult Intelligence Scale-III (for demographic and neuropsychological characteristics, see Table 1). Working memory performance was within normal limits for each of the amnesic patients and $>2$ SD above their episodic memory performance (Table 1). All participants gave written informed consent and received financial compensation. The VA Boston Healthcare System institutional review board approved all experimental procedures.

P01 developed amnesia (extensive retrograde and anterograde amnesia, including an inability to remember daily events) subsequent to herpes simplex encephalitis (age of onset, 45 years). His memory impairment has been stable for over 10 years and he requires assisted living due the magnitude of his memory impairment. Bilateral MTL damage was evident on MRI (left > right; Fig. 1). P01's pathology included left hippocampus [volume -6.4 SD below the mean of ageand education-matched controls as reported in Kan et al. (2007)], left anterior parahippocampal gyrus ( $-3.9 \mathrm{SD})$, and a portion of left posterior parahippocampal gyrus ( $-2.9 \mathrm{SD})$, as well as the left amygdala and temporal pole. On the right, damage was most evident on anterior portion of the hippocampus $(-4.8 \mathrm{SD})$ and anterior parahippocampal gyrus $(-2.3 \mathrm{SD})$.

P02 was struck in the head with a baseball, causing a left cerebral hematoma and convulsion. He subsequently underwent surgery for evacuation of the hematoma. He returned to work part-time with reportedly normal memory function. Three months postinjury, P02 experienced status epilepticus for up to $2 \mathrm{~h}$. Anoxia was associated with this event, as $\mathrm{P} 02$ required intubation with subsequent difficulty weaning from intubation. $\mathrm{P} 02$ has profound anterograde amnesia and extensive retrograde amnesia since this event (age of onset, 25 years). P02's memory impairment has been stable for $\sim 20$ years and he requires assisted living due to memory impairment. He has bilateral MTL damage, left greater than right, and his lesion profile was similar to P01 (Fig. 1). P02's damage included left hippocampus ( $-6.2 \mathrm{SD})$, left anterior parahippocampal gyrus $(-2.2 \mathrm{SD})$, left amygdala, left temporal pole, left lateral temporal cortex, and right hippocampus $(-3.4 \mathrm{SD}$; with damage most evident in the anterior portion).

P03 developed amnesia after anoxia associated with carbon monoxide poisoning (age of onset, 37 years). He suffers from severe anterograde amnesia and mild retrograde amnesia. His memory impairment has been stable for $\sim 17$ years. Although he lives with family, P03 is able to function semi-independently in his own home and within his hometown, but not in new environments. This is attributable to the fact that his retrograde amnesia is relatively mild and the consistency in his home environment, as well as his impressive executive abilities in daily life (copious note taking, reminders, etc.). P03 has circumscribed damage restricted to bilateral hippocampus (hippocampal volume, on the left and right, -1.3 and -2.5 SD, respectively; Fig. 1).

Image acquisition and procedure. After informed consent, participants were placed supine on the MRI ( 3 tesla Siemens Tim Trio scanner with a 12-channel head coil) table, fitted with earplugs and goggles, and had their heads stabilized with cushions. The participants were moved into the bore of the scanner, and a three-plane localizer scan was collected to align a whole-brain T1-weighted structural MP-RAGE sequence acquired in the sagittal plane (TR, $2530 \mathrm{~ms}$; TE, $3.32 \mathrm{~ms}$; TI, $1100 \mathrm{~ms} ; 176$ slices; $256 \times 256$ matrix). Next, whole-brain functional images were 


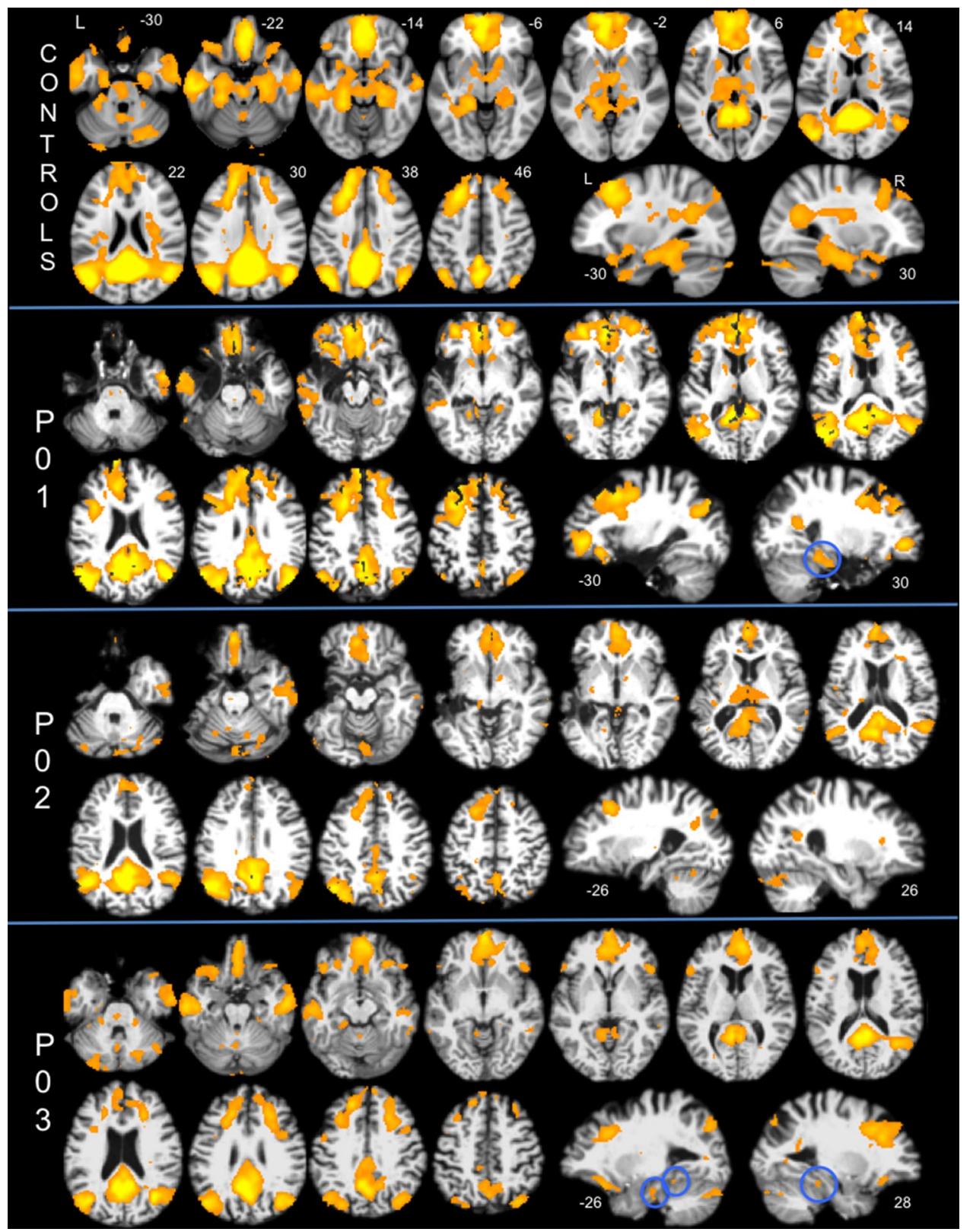

Figure 2. Default network connectivity maps of each amnesic patient (P01, P02, P03) and the group map of 10 age- and education-matched control participants displayed at cluster-corrected $Z>5$. The numbers displayed on the upper right of each axial slice represent the $z$-coordinate in MNI space (the same slices are used for each subject/group map); the numbers below the sagittal slices represent the $x$-coordinate. Default network connectivity to residual MTL tissue in two of three amnesic patients is highlighted with blue circles. L, Left; $R$, right.

acquired parallel to the anterior-posterior commissure plane using an EPI sequence sensitive to the blood oxygen level-dependent (BOLD) signal ( 2 runs; 240 volumes; TR, 2 s; TE, 30 ms; 33 slices; $64 \times 64$ matrix; FOV, 192; voxel size, $3 \mathrm{~mm}^{3}$; spacing, $0.75 \mathrm{~mm}$; interleaved acquisition). During each 8 min functional run, there were 14 trials in which a white cross-hair appeared on a black background for $2.5 \mathrm{~s}$ at random intervals (intertrial interval range, 4-72 s; mean, $35 \mathrm{~s}$ ). Subjects' task was to respond by button press to those trials. Trials were presented using e-prime installed on a PC computer with an MRI-compatible visual display goggle system. Subjects were instructed to rest during the scan, and that the only purpose of the task was to confirm that they were not sleeping (participants completed a brief behavioral practice session on a laptop before entering the scanner). Previous work has demonstrated that the DN can be identified using seed-based connectivity approaches during a low-level task (Greicius et al., 2003) such as that used in the current study. An MRI-compatible fiber-optic response box was used to collect their button presses.
Image processing and analysis. Standard resting-state functional connectivity MRI preprocessing was implemented using FMRI Expert Analysis Tool (FEAT) version 5.98, part of FMRIB Software Library (FSL; www.fmrib.ox.ac.uk/fsl) version 4.1 (Smith et al., 2004; Woolrich et al., 2009). The following prestatistics processing was applied: motion correction using MCFLIRT, slice-timing correction using Fourierspace time-series phase-shifting, nonbrain removal using BET, spatial smoothing using a Gaussian kernel of full-width half-maximum of 6.0 $\mathrm{mm}$, grand-mean intensity normalization of the entire 4D dataset by a single multiplicative factor, high-pass temporal filtering (Gaussianweighted least-squares straight line fitting, with $\sigma=45.0 \mathrm{~s}$ ), and Gaussian low-pass temporal filtering (HWHM $2.8 \mathrm{~s}$ ).

To identify DN connectivity, each subject's functional time series was extracted from an a priori defined $8 \mathrm{~mm}$ posterior cingulate cortex (PCC) spherical seed region (centered on $-8,-56,26$ ), as reported by Andrews-Hanna et al. (2010). PCC was chosen because it is considered a core hub of the DN (Buckner et al., 2009) and is commonly used to 


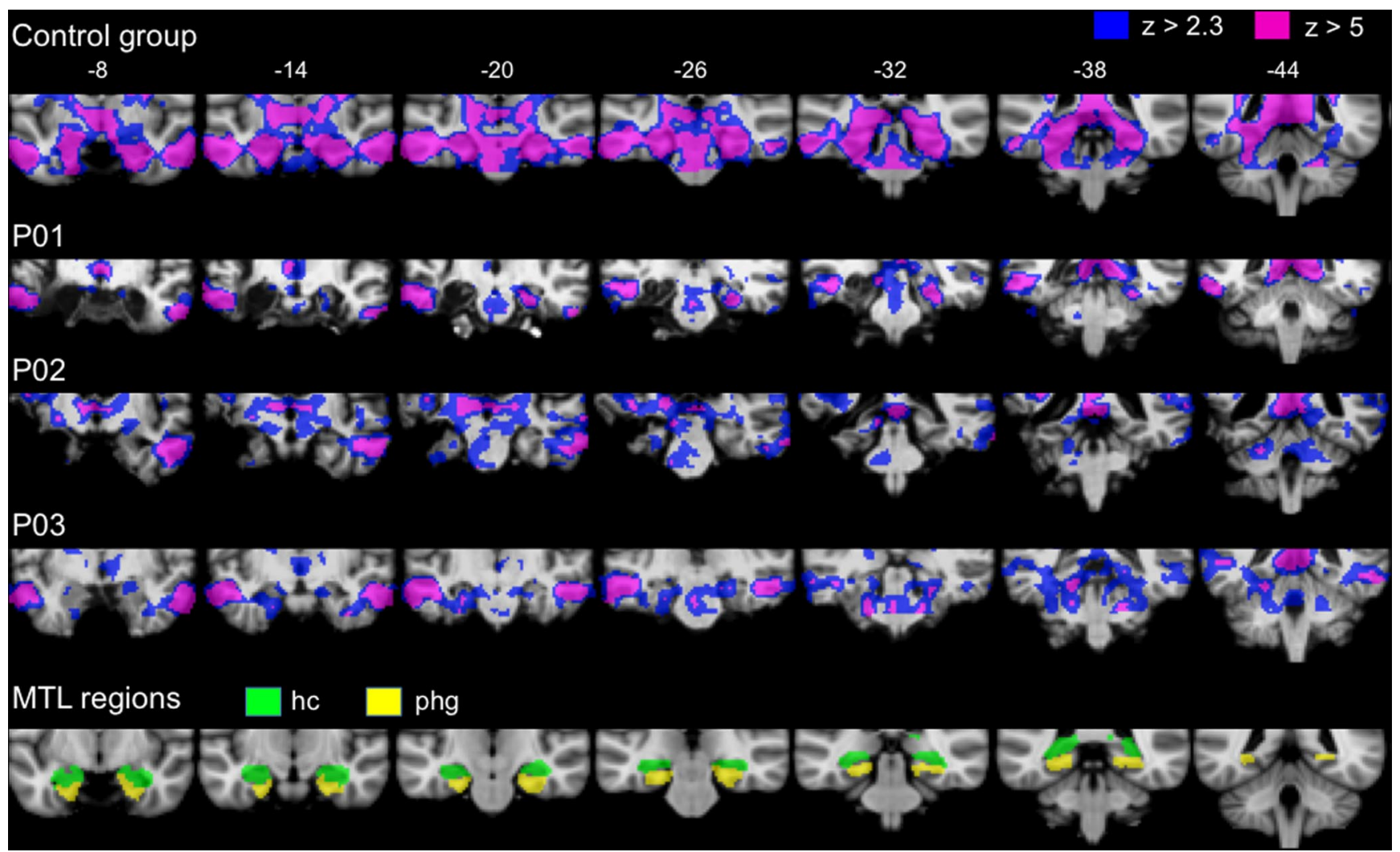

Figure 3. $P C C$ connectivity to residual MTL tissue in amnesic patients and the control group are displayed at two statistical thresholds: cluster-corrected $Z>2.3$ (blue) and $Z>5$ (pink). The numbers along the top represent MNI coordinates in the coronal plane. Individual patient connectivity maps are overlaid on their normalized T1-weighted images. Anatomical masks of the hippocampus (hc, green) and parahippocampal gyrus (phg, yellow) are displayed for reference.

identify the DN using seed-based functional connectivity (Greicius et al., 2003; Fox et al., 2005; Hagmann et al., 2008). The PCC seed was transformed to the individual subject's native space, and signal from all voxels in this PCC seed was averaged to compute the mean PCC seed time series. The mean functional time series from this PCC seed was then correlated with whole-brain activity on a voxelwise basis for every volume in the time series. Regions of interest (ROI) of CSF, white matter, and whole brain were created using FreeSurfer (http://surfer.nmr.mgh.harvard. edu/), and ROIs included all FreeSurfer labels that matched that particular tissue type (Fischl et al., 2004). As with the PCC seed, signal from each of these ROIs was averaged and used to generate a mean functional time series subsequently included as nuisance regressors, along with motion parameters, in the model.

Higher-level analyses were performed using a fixed-effects model, by forcing the random effects variance to zero in FMRIB's Local Analysis of Mixed Effects (FLAME). Lesion masks for P01 and P02 were applied before statistical thresholding. P03's structural damage was not sufficient to warrant masking. Therefore, the results of all functional connectivity individual and group analyses reported in the current study do not include regions of the brain where structural damage was evident on the patient's T1-weighted volume. To examine DN connectivity in each amnesic patient, $Z$ statistic images of PCC connectivity from each run were combined and significant connectivity determined using clusters with $Z>5.0$ and a (corrected) cluster significance threshold of $p=0.05$. To examine regions of increased and decreased connectivity in each patient, a one-sample $t$ test comparing connectivity maps in each patient to controls was performed, $Z>2.3$ and a (corrected) cluster significance threshold of $p=0.05$. Conjunction analysis of the one-sample $t$ test maps derived from each individual patient was performed to demonstrate regions of increased and decreased connectivity common to all three MTL amnesic patients.

To assess whether connectivity changes evident in amnesia were selective to the $\mathrm{DN}$, the somatomotor network was examined as a control network by correlating the residual mean time series (nuisance regressors removed) from right somatomotor cortex (spherical ROI with $8 \mathrm{~mm}$ radius centered on $42,-23,51$ ), which included portions of precentral and postcentral gyrus, with the analogous ROI on the left $(-40,-22,55$ [coordinates derived from Johnston et al. (2008)]) and midline supplementary motor cortex $(0,-24,56)$. Brain figures were created using MRIcron (http://www.mricro.com) (Rorden and Brett, 2000).

\section{Results}

Default network in individual amnesic patients and control group

Despite bilateral lesion to the MTL, functional connectivity analyses (threshold at cluster-corrected $Z>5$ ) revealed robust cortical DN connectivity at the individual subject level in each of the amnesic patients. As seen in Figure 2, DN connectivity extended from the posterior cingulate cortex seed to include canonical DN regions such as precuneus, lateral parietal regions, and medial prefrontal regions in each of the amnesic patients (results from the analysis of the control group, threshold at cluster-corrected $Z>5$, are provided for comparison purposes). In addition, at the individual subject level, DN connectivity was evident in residual MTL regions such as right parahippocampal cortex in P01 and left perirhinal/hippocampal cortex and bilateral parahippocampal cortex in P03 (Fig. 3). When a more lenient threshold was used (cluster-corrected $Z>2.3$ ), evidence of additional MTL connectivity was observed in the right hippocampus in P01 (28, $-30,10$; this cluster included the longitudinal axis of the hippocampus and was an expansion of the right parahippocampal cortex cluster reported above), left parahippocampal cortex in P02 $(-26,-26,-22)$, and bilateral hippocampus in P03 $(-22$, $-26,-12 ; 26,-26,-14)$. When the same methods were imple- 
mented in individual control participants, PCC-MTL connectivity was evident in 10 of 10 participants at $Z>2.3$, and nine of 10 participants at $Z>5$ (see Notes).

\section{Changes in default network common to} MTL amnesia

To examine regions of increased or decreased DN connectivity common to the three patients with MTL lesions, a wholebrain conjunction analysis was performed with the PCC connectivity maps derived from the results of the individual patients' one-sample $t$ test versus controls. Decreased PCC connectivity in amnesic patients relative to controls was observed in residual MTL tissue, including left parahippocampal cortex $(-26,-38,-12)$ and right hippocampus $(32,-20,-16)$ (Fig. $4 a)$, as well as the precuneus $(-12$, $-66,38)$. Increased PCC connectivity in amnesic patients was observed in $\mathrm{DN}$ regions including anteromedial prefrontal cortex, ventromedial prefrontal cortex, posterior inferior parietal lobule, retrosplenial cortex, and posterior cingulate/precuneus (Fig. 4b). A complete list of regions showing functional connectivity changes common to MTL amnesia is presented in Table 2.

\section{Somatomotor network connectivity in MTL amnesia}

No consistent differences were observed in somatomotor network ROIs in the amnesic patients relative to control participants (Fig. 5).

\section{Discussion}

To our knowledge, this is the first study to examine the impact of bilateral MTL lesions on a large-scale functional neural network associated with episodic memory, the DN. At the individual subject level, amnesic patients exhibited connectivity to cortical nodes of the DN as well as to residual MTL tissue. However, spontaneous BOLD signal fluctuations in PCC and residual MTL structures were less synchronized in amnesia compared with controls. In contrast, increased signal coupling was observed in amnesia between PCC and canonical cortical DN regions including medial prefrontal cortex, posterior midline regions, and bilateral parietal regions. Importantly, somatomotor network connectivity in amnesic patients was largely within normal limits. These results suggest that bilateral MTL lesions can selectively impact the DN.

In the current study, resting fMRI was used to examine the impact of structural lesion on intrinsic functional interactions between neuronal regions composing a large-scale neural network. Previous work in animals has illuminated the structural connections that provide the anatomical scaffolding for functional connectivity of the DN. For instance, primate-tracing studies have demonstrated that PCC, the seed region used to identify

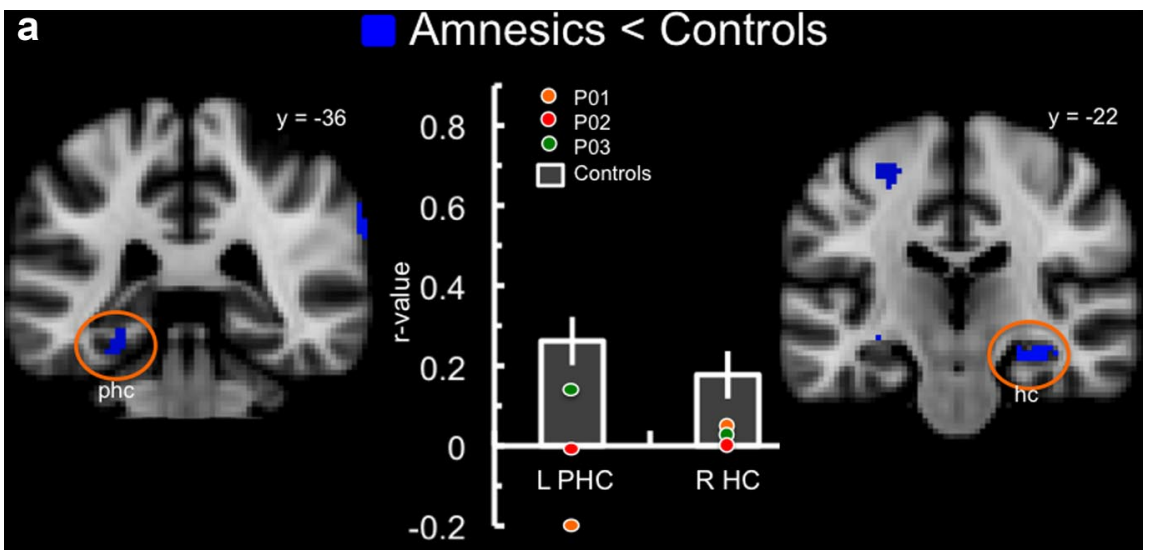

b Amnesics > Controls

Figure 4. Results of the whole-brain conjunction analyses of default network connectivity in amnesic patients relative to controls. Changes observed in default network regions are highlighted with anatomical labels and/or orange circles. Bar graphs represent the correlation coefficient (SEM) of the PCC time series with the specified brain region in the control group. The colored nesic patients relative to controls in default network regions including left parahippocampal cortex and right hippocampus. $\boldsymbol{b}$ posterior-medial cortex, and bilateral parietal regions. amPFC, Anterior medial prefrontal cortex; HC, hippocampus; L, left; PHC, parahippocampal cortex; pIPL, posterior inferior parietal lobule; $R$, right; RSP, retrosplenial cortex; vmPFC, ventromedial prefrontal cortex.

the DN in the current study, has connections that terminate in retrosplenial cortex, medial parietal cortex (precuneus), and posterior inferior parietal lobes (Parvizi et al., 2006; Schmahmann and Pandya, 2006). PCC also has direct connections to the MTL, including entorhinal cortex (Parvizi et al., 2006), which has direct connections to the hippocampus via both the polysynaptic and direct intrahippocampal pathway (Duvernoy, 2005; Parvizi et al., 2006). In addition, one of the primary long association fibers of PCC is the cingulum bundle, through which PCC has connections that terminate in anterior medial prefrontal cortex, as well as presubiculum and parahippocampal gyrus white matter (Schmahmann and Pandya, 2006).

Although structural studies in animals have revealed PCCMTL connectivity, early examination of the DN did not include hippocampus or parahippocampal gyrus as nodes of the 
Table 2. Results of the whole-brain conjunction analysis of default network connectivity in amnesic patients versus controls

\begin{tabular}{|c|c|c|c|c|c|}
\hline \multirow[b]{2}{*}{ Analysis/brain region } & \multirow[b]{2}{*}{ Hemisphere } & \multirow[b]{2}{*}{$k$} & \multicolumn{3}{|c|}{ MNI coordinates } \\
\hline & & & $x$ & $y$ & $z$ \\
\hline \multicolumn{6}{|l|}{ Amnesic patients $<$ Controls } \\
\hline \multicolumn{6}{|l|}{ Default network regions } \\
\hline Hippocampus & $\mathrm{R}$ & 118 & 32 & -20 & -16 \\
\hline Parahippocampal cortex & L & 57 & -26 & -38 & -12 \\
\hline Thalamus & L & 69 & -22 & -32 & -2 \\
\hline Precuneus & L & 680 & -12 & -66 & 38 \\
\hline Cuneus & L & & -22 & -78 & 24 \\
\hline Precuneus & L & 101 & -6 & -46 & 40 \\
\hline Superior frontal gyrus & $\mathrm{R}$ & 26 & 6 & 62 & 22 \\
\hline Putamen & $\mathrm{R}$ & 16 & 22 & 4 & -12 \\
\hline \multicolumn{6}{|l|}{ Regions outside of default network } \\
\hline Supramarginal gyrus & $\mathrm{R}$ & 101 & 62 & -30 & 30 \\
\hline Superior parietal lobule/angular gyrus & $\mathrm{R}$ & 68 & 36 & -54 & 50 \\
\hline Pars opercularis & $\mathrm{R}$ & 88 & 60 & 12 & 12 \\
\hline Pars triangularis & $\mathrm{R}$ & 25 & 38 & 34 & 4 \\
\hline Rostral middle frontal gyrus & $\mathrm{R}$ & 64 & 42 & 34 & 36 \\
\hline Rostral middle frontal gyrus & $\mathrm{R}$ & 39 & 38 & 38 & 12 \\
\hline Caudal anterior cingulate & $\mathrm{R}$ & 58 & 8 & 18 & 24 \\
\hline Lateral orbitofrontal cortex & $\mathrm{R}$ & 17 & 38 & 26 & -14 \\
\hline Insula & L & 19 & -34 & 14 & 0 \\
\hline Amygdala & $\mathrm{R}$ & 37 & 30 & 0 & -16 \\
\hline Occipital pole & L & 503 & -20 & -102 & -6 \\
\hline Occipital pole & $\mathrm{R}$ & 244 & 20 & -100 & 4 \\
\hline Lateral occipital cortex & $\mathrm{R}$ & 106 & 32 & -82 & 16 \\
\hline Precentral gyrus & $\mathrm{R}$ & 362 & 50 & -6 & 48 \\
\hline Precentral gyrus & L & 93 & -56 & 6 & 14 \\
\hline Precentral gyrus & $\mathrm{L}$ & 54 & -30 & -24 & 56 \\
\hline \multicolumn{6}{|l|}{ Amnesic patients $>$ Controls } \\
\hline \multicolumn{6}{|l|}{ Default network regions } \\
\hline Rostral anterior cingulate/vmPFC & $\mathrm{R}$ & 881 & 6 & 26 & -14 \\
\hline Rostral anterior cingulate/amPFC & $\mathrm{R}$ & & 6 & 50 & 0 \\
\hline Rostral anterior cingulate/vmPFC & L & & -4 & 26 & 18 \\
\hline Rostral anterior cingulate/amPFC & L & & -4 & 48 & -2 \\
\hline Medial frontal gyrus/DMPFC & L & & -6 & 60 & 12 \\
\hline Medial frontal gyrus & $\mathrm{L}$ & 17 & -4 & 66 & 4 \\
\hline Superior frontal gyrus & L & 214 & -6 & 48 & 36 \\
\hline Superior frontal gyrus & $\mathrm{R}$ & 49 & 12 & 46 & 36 \\
\hline Middle/superior frontal gyrus & L & 36 & -24 & 18 & 38 \\
\hline Posterior cingulate cortex & L & 740 & -8 & -54 & 24 \\
\hline Posterior cingulate cortex & $\mathrm{R}$ & & 6 & -46 & 22 \\
\hline Retrosplenial cortex & $\mathrm{L}$ & & -18 & -54 & 6 \\
\hline Posterior inferior parietal lobe & $\mathrm{L}$ & 318 & -46 & -72 & 36 \\
\hline Posterior inferior parietal lobe & L & 129 & -32 & -76 & 36 \\
\hline Posterior inferior parietal lobe & $\mathrm{R}$ & 41 & 36 & -74 & 48 \\
\hline Posterior inferior parietal lobe & $\mathrm{R}$ & 57 & 46 & -74 & 30 \\
\hline Angular gyrus & $\mathrm{R}$ & 235 & 44 & -54 & 16 \\
\hline Middle/inferior temporal gyrus & $\mathrm{R}$ & 127 & 56 & -6 & -30 \\
\hline \multicolumn{6}{|l|}{ Regions outside of default network } \\
\hline Medial frontal gyrus & L & 17 & -6 & 12 & 60 \\
\hline Medial frontal gyrus & L & 108 & -12 & 22 & 52 \\
\hline Rostral middle frontal gyrus & $\mathrm{R}$ & 103 & 42 & 4 & 36 \\
\hline Posterior superior frontal gyrus & $\mathrm{R}$ & 46 & 22 & 10 & 48 \\
\hline Supramarginal gyrus & $\mathrm{R}$ & 35 & 46 & -40 & 26 \\
\hline Precuneus & R & 27 & 6 & -54 & 60 \\
\hline Banks of superior temporal sulcus & L & 85 & -46 & -52 & 4 \\
\hline Inferior temporal gyrus & L & 19 & -58 & -60 & -14 \\
\hline Lingual gyrus & $\mathrm{L}$ & 55 & -8 & -78 & -12 \\
\hline
\end{tabular}

Changes that occurred within the group PCC connectivity map were considered to be within the DN, whereas changes outside of the map were classified as regions outside of the DN. L, Left; $R$, right; $k$, voxel extent; amPFC, anterior medial prefrontal cortex; vmPFC, ventromedial prefrontal cortex.

DN (Shulman et al., 1997; Raichle et al., 2001). However, recent $\mathrm{fMRI}$ studies in humans have highlighted these regions as reliable nodes of the DN (Greicius and Menon, 2004; Greicius et al., 2004, 2009; Vincent et al., 2006; Andrews-Hanna et al., 2010), along with the posterior cingulate/precuneus, bilat-

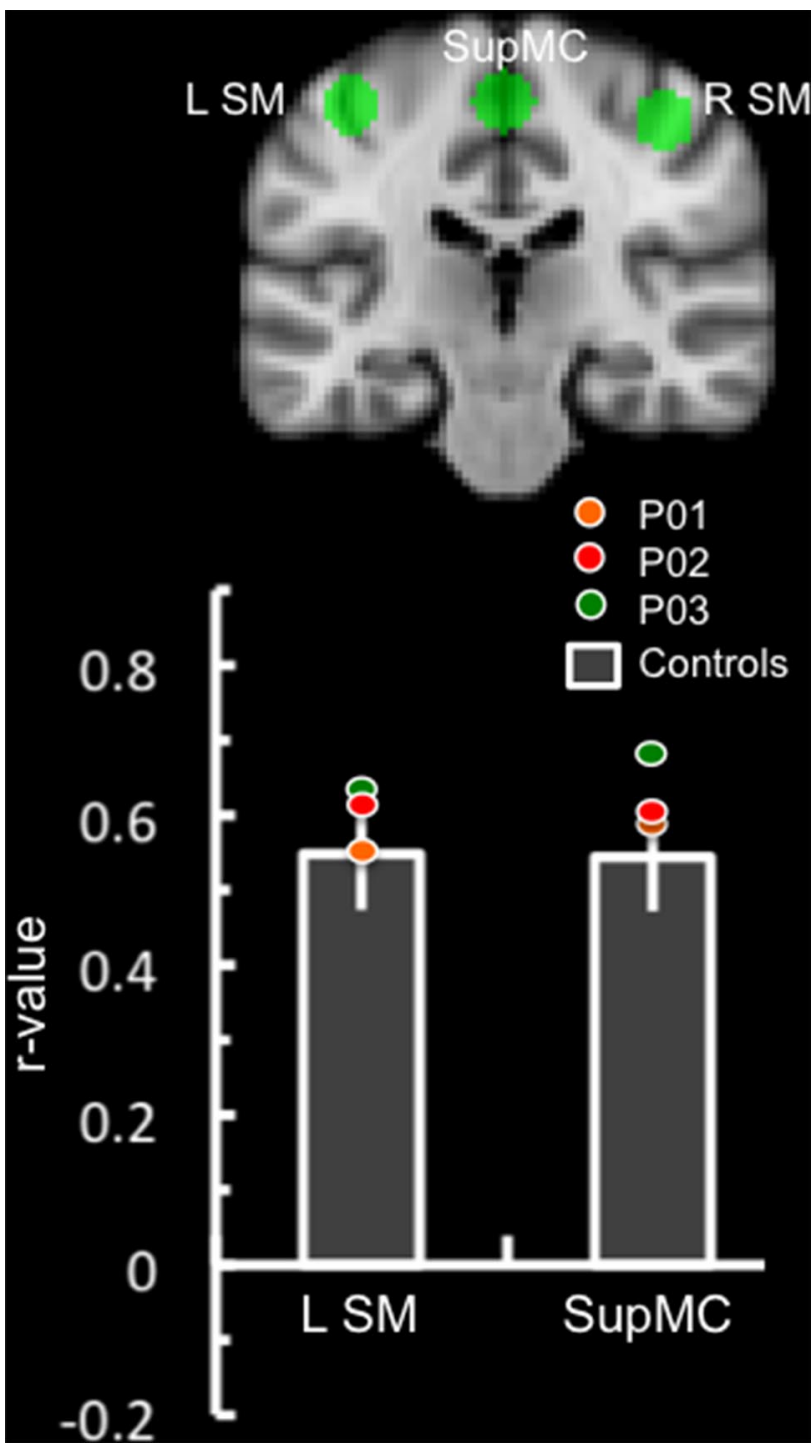

Figure 5. Results of somatomotor network ROl analysis. Somatomotor network regions of interest are displayed in the coronal plane $(y=-24)$. Bar graphs represent the correlation coefficient (SEM) of the right somatomotor cortex (R SM) time series with the analogous region on the left somatomotor cortex (LSM) and supplementary motor cortex (SupMC) in the control group. The colored circles represent each individual patient's correlation coefficient.

eral parietal cortex, lateral temporal cortex, and medial prefrontal cortex (Buckner et al., 2008).

In the current study, decreased PCC connectivity was observed to residual hippocampus and parahippocampal gyrus in amnesic patients relative to controls. This finding likely reflects the underlying structural damage to the MTL in patients. Similar decreases in PCC-MTL connectivity have been reported in epilepsy patients with unilateral MTL atrophy (and in some cases, sclerosis), with decreases typically restricted to the hemisphere in which the seizure focus was localized (Bettus et al., 2009; Pereira et al., 2010; Liao et al., 2011). Nonetheless, there was significant functional connectivity to residual MTL tissue at the individual patient level in the current study, but this connectivity is not sufficient to overcome episodic memory deficits resulting from bilateral hippocampal damage. Because of the rarity of MTL amnesic patients, our sample size was restricted and we were not able to 
assess whether the strength of MTL connectivity was related to the degree of behavioral impairment (and, as noted above, such analyses may be subject to floor effects).

Our findings contrast with a case report of developmental amnesia, in which increased MTL connectivity was observed during autobiographical memory retrieval (Maguire et al., 2001). In developmental amnesia, increased MTL connectivity may represent a compensatory response, as these patients are able to recollect some events. Furthermore, given the perinatal onset of neurological insult in developmental amnesia, the brain may be better able to formulate an adaptive response relative to the adult-onset cases presented in the current study. Consistent with this notion, recent work has highlighted the relative integrity of resting-state networks in congenital agenesis of the corpus callosum (Tyszka et al., 2011).

Could reduced MTL functional connectivity in our cases of adult onset amnesia reflect a fundamental disruption of function, rather than anatomy? We were unable to assess patients' spontaneous internal mentation during scanning. Given evidence that remembering the past and envisioning the future, both of which are impaired in amnesia (Hassabis et al., 2007; but see Squire et al., 2010; Race et al., 2011), are a major focus of spontaneous thought (AndrewsHanna et al., 2010), disrupted functional connectivity might be the consequence of a reduction in spontaneous thoughts during rest in amnesic patients compared with controls. However, in our patients, a reduced tendency to think about the past and/or future in itself reflects disrupted MTL anatomy (i.e., reduced memory ability is a result of the anatomical lesion). Further, if our pattern of results were simply a reflection of a reduction in spontaneous thinking, one would expect a consistent pattern of decreased connectivity across regions associated with the DN and with spontaneous thought (Mason et al., 2007; Christoff et al., 2009) rather than the pattern of both decreases and increases in connectivity that we observed.

In the current study, the increased PCC functional connectivity observed in DN regions distal to the structural lesion, such as retrosplenial cortex, lateral parietal cortex, ventromedial prefrontal cortex, and anteromedial prefrontal cortex, is consistent with studies demonstrating increased functional connectivity within the DN in epilepsy patients (Addis et al., 2007; Bettus et al., 2009; Luo et al., 2011). These increases in connectivity may result from changes in connectivity dynamics as a result of structural lesion. That is, loss of afferents from the MTL may result in enhanced coupling between remaining nodes of the system, a phenomenon that has been referred to as connectional diaschisis (Campo et al., 2012). Alternatively, the enhanced connectivity could represent a compensatory response (Addis et al., 2007). Given the magnitude of the memory deficit in the amnesic patients, it is challenging to interpret the increased connectivity in DN regions observed in the current study as a compensatory response (in terms of positively impacting memory). A more likely explanation is that the increased connectivity represents a pathophysiological response to MTL lesion.

It has recently been proposed that the $\mathrm{DN}$ is composed of two interacting subsystems: a MTL system and a dorsomedial prefrontal cortex (DMPFC) system (Table 3). Both subsystems interact with core hubs: PCC and the anterior medial prefrontal cortex (Buckner et al., 2008; Andrews-Hanna et al., 2010). The proposal is supported by a combination of graph-analytic and hierarchical clustering techniques, as well as results of taskrelated fMRI targeting cognitive functions hypothesized to rely more heavily on the MTL or dorsomedial prefrontal cortex subsystem. For instance, future thinking, which is thought to be mediated by episodic memory (Schacter et al., 2007) and is also impaired in amnesia (Hassabis et al., 2007; Race et al., 2011),
Table 3. Classification of default network regions and the results of functional connectivity analysis in amnesic patients relative to control participants

Functional connectivity

\begin{tabular}{ll}
\hline Core & \\
Anterior medial prefrontal cortex & Increase \\
Posterior cingulate cortex & Increase (seed region) \\
Medial temporal lobe subsystem & \\
Hippocampal formation & Decrease \\
Parahippocampal cortex & Decrease \\
Retrosplenial cortex & Increase \\
Posterior inferior parietal lobe & Increase \\
Ventromedial prefrontal cortex & Increase \\
Dorsomedial prefrontal cortex subsystem & \\
DMPFC & - \\
Tempoparietal junction & - \\
Lateral temporal cortex & - \\
Temporal pole & - \\
\hline
\end{tabular}

Regions designated as an increase or decrease if the connectivity changes overlapped with $8 \mathrm{~mm}$ spheres centered on ROls, as reported by Andrews-Hanna et al. (2010). - , No changes observed.

preferentially activated the MTL subsystem of the DN, whereas self-referential judgments about one's present (as opposed to future) self preferentially activated the DMPFC system (AndrewsHanna et al., 2010).

Alterations in functional connectivity in patients with amnesia were observed distal to the structural damage, but the abnormal responses (both increased and decreased connectivity) observed within DN regions occurred primarily within nodes associated with the MTL subsystem rather than the DMPFC subsystem (Table 3 ). It should be noted that there were connectivity changes in amnesia in regions of DMPFC (Table 2), although they did not overlap with the DMPFC ROI reported by AndrewsHanna et al. (2010). In contrast, connectivity changes noted in the MTL subsystem did overlap with the ROIs reported. Given the impairment in episodic memory and reports of impaired future thinking in amnesia (Hassabis et al., 2007; Race et al., 2011), the observed pattern of alterations in intrinsic functional connectivity in MTL amnesia provides preliminary support from patients that the DN can be fractionated into functionally and structurally distinct components.

In conclusion, resting-state connectivity analysis allows for the examination of functional networks in patient populations unable to complete traditional task-based fMRI paradigms due to cognitive limitations. The current study examined DN connectivity in amnesic patients with bilateral MTL damage. DN connectivity in individual amnesic patients was relatively intact in canonical cortical DN nodes, including medial prefrontal cortex, posterior medial parietal cortex, and lateral parietal cortex. There was also evidence of connectivity to residual MTL tissue at the individual level in amnesic patients. Results of a conjunction analysis revealed reductions in connectivity between PCC and left parahippocampal cortex and PCC and right hippocampus common to amnesia. In addition, increased PCC connectivity was observed in cortical DN regions such as retrosplenial cortex, posterior inferior lateral parietal cortex, and medial prefrontal regions. These results highlight the utility of integrating resting fMRI data with lesion data, and provide preliminary support from patients that the DN is composed of distinct subsystems.

\section{Notes}

Supplemental Figure 1 for this article is available at http://www.bu. edu/brainlab/files/2012/07/Hayes_SupFig1.pdf. This material has not been peer reviewed. 


\section{References}

Addis DR, Moscovitch M, McAndrews MP (2007) Consequences of hippocampal damage across the autobiographical memory network in left temporal lobe epilepsy. Brain 130:2327-2342. CrossRef Medline

Andreasen NC, O'Leary DS, Cizadlo T, Arndt S, Rezai K, Watkins GL, Ponto LL, Hichwa RD (1995) Remembering the past: two facets of episodic memory explored with positron emission tomography. Am J Psychiatry 152:1576-1585. Medline

Andrews-Hanna JR, Reidler JS, Sepulcre J, Poulin R, Buckner RL (2010) Functional-anatomic fractionation of the brain's default network. Neuron 65:550-562. CrossRef Medline

Bettus G, Guedj E, Joyeux F, Confort-Gouny S, Soulier E, Laguitton V, Cozzone PJ, Chauvel P, Ranjeva JP, Bartolomei F, Guye M (2009) Decreased basal fMRI functional connectivity in epileptogenic networks and contralateral compensatory mechanisms. Hum Brain Mapp 30:1580-1591. CrossRef Medline

Buckner RL, Andrews-Hanna JR, Schacter DL (2008) The brain's default network: anatomy, function, and relevance to disease. Ann N Y Acad Sci 1124:1-38. CrossRef Medline

Buckner RL, Sepulcre J, Talukdar T, Krienen FM, Liu H, Hedden T, AndrewsHanna JR, Sperling RA, Johnson KA (2009) Cortical hubs revealed by intrinsic functional connectivity: mapping, assessment of stability, and relation to Alzheimer's disease. J Neurosci 29:1860-1873. CrossRef Medline

Campo P, Garrido MI, Moran RJ, Maestú F, García-Morales I, Gil-Nagel A, del Pozo F, Dolan RJ, Friston KJ (2012) Remote effects of hippocampal sclerosis on effective connectivity during working memory encoding: a case of connectional diaschisis? Cereb Cortex 22:1225-1236. CrossRef Medline

Christoff K, Gordon AM, Smallwood J, Smith R, Schooler JW (2009) Experience sampling during fMRI reveals default network and executive system contributions to mind wandering. Proc Natl Acad Sci U S A 106:8719-8724. CrossRef Medline

Daselaar SM, Prince SE, Dennis NA, Hayes SM, Kim H, Cabeza R (2009) Posterior midline and ventral parietal activity is associated with retrieval success and encoding failure. Front Hum Neurosci 3:13. Medline

Duvernoy HM (2005) The human hippocampus: functional anatomy, vascularization, and serial sections with MRI, 3rd edition. Berlin: Springer.

Eichenbaum H, Yonelinas AP, Ranganath C (2007) The medial temporal lobe and recognition memory. Ann Rev Neurosci 30:123-152. CrossRef Medline

Fischl B, van der Kouwe A, Destrieux C, Halgren E, Ségonne F, Salat DH, Busa E, Seidman LJ, Goldstein J, Kennedy D, Caviness V, Makris N, Rosen B, Dale AM (2004) Automatically parcellating the human cerebral cortex. Cereb Cortex 14:11-22. CrossRef Medline

Fox MD, Snyder AZ, Vincent JL, Corbetta M, Van Essen DC, Raichle ME (2005) The human brain is intrinsically organized into dynamic, anticorrelated functional networks. Proc Natl Acad Sci U S A 102:9673-9678. CrossRef Medline

Frings L, Schulze-Bonhage A, Spreer J, Wagner K (2009) Remote effects of hippocampal damage on default network connectivity in the human brain. J Neurol 256:2021-2029. CrossRef Medline

Greicius MD, Menon V (2004) Default-mode activity during a passive sensory task: uncoupled from deactivation but impacting activation. J Cogn Neurosci 16:1484-1492. CrossRef Medline

Greicius MD, Krasnow B, Reiss AL, Menon V (2003) Functional connectivity in the resting brain: A network analysis of the default mode hypothesis. Proc Natl Acad Sci U S A 100:253-258. CrossRef Medline

Greicius MD, Srivastava G, Reiss AL, Menon V (2004) Default-mode network activity distinguishes Alzheimer's disease from healthy aging: evidence from functional MRI. Proc Natl Acad Sci U S A 101:4637-4642. CrossRef Medline

Greicius MD, Supekar K, Menon V, Dougherty RF (2009) Resting-state functional connectivity reflects structural connectivity in the default mode network. Cereb Cortex 19:72-78. Medline

Hagmann P, Cammoun L, Gigandet X, Meuli R, Honey CJ, Wedeen VJ, Sporns O (2008) Mapping the structural core of human cerebral cortex. PLoS Biol 6:e159. CrossRef Medline

Hassabis D, Kumaran D, Vann SD, Maguire EA (2007) Patients with hippocampal amnesia cannot imagine new experiences. Proc Natl Acad Sci U S A 104:1726-1731. CrossRef Medline

Johnston JM, Vaishnavi SN, Smyth MD, Zhang D, He BJ, Zempel JM, Shi- mony JS, Snyder AZ, Raichle ME (2008) Loss of resting interhemispheric functional connectivity after complete section of the corpus callosum. J Neurosci 28:6453-6458. CrossRef Medline

Kan IP, Giovanello KS, Schnyer DM, Makris N, Verfaellie M (2007) Role of the medial temporal lobes in relational memory: neuropsychological evidence from a cued recognition paradigm. Neuropsychologia 45:2589-2597. CrossRef Medline

Liao W, Zhang Z, Pan Z, Mantini D, Ding J, Duan X, Luo C, Wang Z, Tan Q, Lu G, Chen H (2011) Default mode network abnormalities in mesial temporal lobe epilepsy: a study combining fMRI and DTI. Hum Brain Mapp 32:883-895. CrossRef Medline

Luo C, Li Q, Lai Y, Xia Y, Qin Y, Liao W, Li S, Zhou D, Yao D, Gong Q (2011) Altered functional connectivity in default mode network in absence epilepsy: a resting-state fMRI study. Hum Brain Mapp 32:438-449. CrossRef Medline

Maguire EA, Vargha-Khadem F, Mishkin M (2001) The effects of bilateral hippocampal damage on fMRI regional activations and interactions during memory retrieval. Brain 124:1156-1170. CrossRef Medline

Mason MF, Norton MI, Van Horn JD, Wegner DM, Grafton ST, Macrae CN (2007) Wandering minds: the default network and stimulus-independent thought. Science 315:393-395. CrossRef Medline

Mazoyer B, Zago L, Mellet E, Bricogne S, Etard O, Houdé O, Crivello F, Joliot M, Petit L, Tzourio-Mazoyer N (2001) Cortical networks for working memory and executive functions sustain the conscious resting state in man. Brain Res Bull 54:287-298. CrossRef Medline

O'Keefe J, Nadel L (1978) The hippocampus as a cognitive map. Oxford: Oxford UP

Parvizi J, Van Hoesen GW, Buckwalter J, Damasio A (2006) Neural connections of the posteromedial cortex in the macaque. Proc Natl Acad Sci U S A 103:1563-1568. CrossRef Medline

Pereira FR, Alessio A, Sercheli MS, Pedro T, Bilevicius E, Rondina JM, Ozelo HF, Castellano G, Covolan RJ, Damasceno BP, Cendes F (2010) Asymmetrical hippocampal connectivity in mesial temporal lobe epilepsy: evidence from resting state fMRI. BMC Neurosci 11:66. CrossRef Medline

Price CJ, Warburton EA, Moore CJ, Frackowiak RS, Friston KJ (2001) Dynamic diaschisis: anatomically remote and context-sensitive human brain lesions. J Cogn Neurosci 13:419-429. CrossRef Medline

Race E, Keane MM, Verfaellie M (2011) Medial temporal lobe damage causes deficits in episodic memory and episodic future thinking not attributable to deficits in narrative construction. J Neurosci 31:10262-10269. CrossRef Medline

Raichle ME, MacLeod AM, Snyder AZ, Powers WJ, Gusnard DA, Shulman GL (2001) A default mode of brain function. Proc Natl Acad Sci U S A 98:676-682. CrossRef Medline

Rorden C, Brett M (2000) Stereotaxic display of brain lesions. Behav Neurol 12:191-200. Medline

Schacter DL, Addis DR, Buckner RL (2007) Remembering the past to imagine the future: the prospective brain. Nat Rev Neurosci 8:657-661. CrossRef Medline

Schmahmann JD, Pandya DN (2006) Fiber pathways of the brain. New York: Oxford UP.

Scoville WB, Milner B (1957) Loss of recent memory after bilateral hippocampal lesions. J Neurol Neurosurg Psychiatry 20:11-21. CrossRef Medline

Shulman GL, Fiez JA, Corbetta M, Buckner RL, Miezin FM, Raichle ME, Petersen SE (1997) Common blood flow changes across visual tasks. 2. Decreases in cerebral cortex. J Cogn Neurosci 9:648-663. CrossRef

Smith SM, Jenkinson M, Woolrich MW, Beckmann CF, Behrens TE, Johansen-Berg H, Bannister PR, De Luca M, Drobnjak I, Flitney DE, Niazy RK, Saunders J, Vickers J, Zhang Y, De Stefano N, Brady JM, Matthews PM (2004) Advances in functional and structural MR image analysis and implementation as FSL. Neuroimage 23 [Suppl 1]:S208-S219. CrossRef Medline

Sperling RA, Dickerson BC, Pihlajamaki M, Vannini P, LaViolette PS, Vitolo OV, Hedden T, Becker JA, Rentz DM, Selkoe DJ, Johnson KA (2010) Functional alterations in memory networks in early Alzheimer's disease. Neuromolecular Med 12:27-43. CrossRef Medline

Spreng RN, Mar RA, Kim AS (2009) The common neural basis of autobiographical memory, prospection, navigation, theory of mind, and the default mode: a quantitative meta-analysis. J Cogn Neurosci 21:489-510. CrossRef Medline 
Squire LR, Stark CE, Clark RE (2004) The medial temporal lobe. Annu Rev Neurosci 27:279-306. CrossRef Medline

Squire LR, van der Horst AS, McDuff SG, Frascino JC, Hopkins RO, Mauldin KN (2010) Role of the hippocampus in remembering the past and imagining the future. Proc Natl Acad Sci U S A 107:19044-19048. CrossRef Medline

Tyszka JM, Kennedy DP, Adolphs R, Paul LK (2011) Intact bilateral restingstate networks in the absence of the corpus callosum. J Neurosci 31: 15154-15162. CrossRef Medline
Vincent JL, Snyder AZ, Fox MD, Shannon BJ, Andrews JR, Raichle ME, Buckner RL (2006) Coherent spontaneous activity identifies a hippocampal-parietal memory network. J Neurophysiol 96:3517-3531. CrossRef Medline

Woolrich MW, Jbabdi S, Patenaude B, Chappell M, Makni S, Behrens T, Beckmann C, Jenkinson M, Smith SM (2009) Bayesian analysis of neuroimaging data in FSL. Neuroimage 45:S173-S186. CrossRef Medline 